\title{
Using task analysis to generate evidence for strengthening midwifery education, practice, and regulation in Ethiopia
}

This article was published in the following Dove Press journal:

International Journal of Women's Health

27 May 2016

Number of times this article has been viewed

\section{Tegbar Yigzaw' \\ Catherine Carr ${ }^{2}$ \\ Jelle Stekelenburg ${ }^{3,4}$ \\ Jos van Roosmalen ${ }^{5}$ \\ Hannah Gibson' \\ Mintwab Gelagay' \\ Azeb Admassu ${ }^{6}$}

'Jhpiego, Addis Ababa, Ethiopia; 2'hpiego, Washington DC, USA;

${ }^{3}$ Department of Obstetrics and Gynecology, Leeuwarden Medical

Centre, Leeuwarden, ${ }^{4}$ Department of Health Sciences, Global Health, University Medical Centre Groningen, University of Groningen, Groningen,

${ }^{5}$ Faculty of Earth and Life Sciences, Vrije Universiteit, Amsterdam, the Netherlands; ${ }^{6}$ Federal Ministry of Health, Addis Ababa, Ethiopia
Correspondence: Tegbar Yigzaw Jhpiego, Kirkos Subcity, PO Box 288I, Code 1250, Addis Ababa, Ethiopia

$\mathrm{Tel}+25$ I I 9 II 408682

Fax +25I I II5 508 8I4

Email tegbar.yigzaw@jhpiego.org
Purpose: Realizing aspirations for meeting the global reproductive, maternal, newborn, and child health goals depends not only on increasing the numbers but also on improving the capability of midwifery workforce. We conducted a task analysis study to identify the needs for strengthening the midwifery workforce in Ethiopia.

Methods: We conducted a cross-sectional study of recently qualified midwives in Ethiopia. Purposively selected participants from representative geographic and practice settings completed a self-administered questionnaire, making judgments about the frequency of performance, criticality, competence, and location of training for a list of validated midwifery tasks. Using Statistical Package for the Social Sciences, Version 20, we computed the percentages and averages to describe participant and practice characteristics. We identified priority preservice education gaps by considering the tasks least frequently learned in preservice, most frequently mentioned for not being trained, and had the highest not capable response. Identification of top priorities for in-service training considered tasks with highest "not capable" and "never" done responses. We determined the licensing exam blueprint by weighing the composite mean scores for frequency and criticality variables and expert rating across practice categories.

Results: One hundred and thirty-eight midwives participated in the study. The majority of respondents recognized the importance of midwifery tasks (89\%), felt they were capable $(91.8 \%)$, reported doing them frequently $(63.9 \%)$, and learned them during preservice education $(56.3 \%)$. We identified competence gaps in tasks related to obstetric complications, gynecology, public health, professional duties, and prevention of mother to child transmission of HIV. Moreover, our study helped to determine composition of the licensing exam for university graduates.

Conclusion: The task analysis indicates that midwives provide critical reproductive, maternal, newborn, and child health care services and supports continuing investment in this cadre. However, there were substantial competence gaps that limit their ability to accelerate progress toward health development goals. Moreover, basing the licensure exam on task analysis helped to ground it in national practice priorities.

Keywords: midwife, perceived importance of tasks, frequency of performance, competence, in-service training needs, licensing exam blueprint

\section{Introduction}

Calls for transforming and scaling up the health workforce as a prerequisite for strengthening health systems and accelerating progress toward universal health coverage have never been stronger. ${ }^{1-4}$ It has also become clear that realizing aspirations for universal health coverage depends not only on increasing workforce numbers but also on improving its capability. Health system challenges in the 21 st century require 
comprehensive health workforce strategies that transform performance and quality along with availability, accessibility, and acceptability. ${ }^{2}$

In the context of attaining national and international development goals for maternal and child health, this means transforming the midwifery workforce. With mounting evidence indicating reproductive, maternal, newborn, and child health (RMNCH) services by competent midwives can avert most maternal deaths, stillbirths, and newborn deaths, the preferred policy option is to invest in the midwifery workforce. ${ }^{5-8}$ Accordingly, many highmortality, low- and middle-income countries have scaled up education and deployment of midwives. ${ }^{8,9}$ In Ethiopia, the number of midwives dramatically increased from 1,379 in 2008 to 9,244 in $2014 .{ }^{10}$ This is due to rapid expansion of midwifery education resulting in annual graduation outputs rising above 2,000. There are three types of undergraduate midwifery education programs in Ethiopia: direct entry university program leading to degree, direct entry vocational program leading to diploma, and postbasic nurse-midwife vocational program leading to diploma qualification. ${ }^{11}$

However, there is limited published data on the actual work of recently deployed midwives. Without such research evidence, it is difficult to know the effectiveness of current strategies and to improve the capability of midwives. Task, job, or practice analysis is a systematic assessment of knowledge and skills that characterize a professional practice. ${ }^{12}$ As such, a task analysis study can generate evidence on current performance of midwives and thereby serve as a data-driven method to identify the needs for strengthening the midwife workforce. We conducted this study to analyze actual on-the-job performance of midwives, identify the needs for strengthening midwifery education and training, and guide licensing exam blueprint development.

\section{Materials and methods Design}

We conducted a cross-sectional study from December 9 to 13,2013 to analyze the tasks performed by practicing midwives in Ethiopia.

\section{Setting}

Midwives from the four most populous and agrarian regions (Tigray, Amhara, Oromia, and Southern Nations, Nationalities, and Peoples), two of the three urban regions (Addis Ababa, Harari), and one of the four relatively less-developed regions (Somali) participated in the study, covering seven out of the eleven regional states and city administrations, home to $96 \%$ of Ethiopia's population.

\section{Participants}

Recently qualified midwives with 6 months to 4 years of work experience participated in the study. The rationale for limiting the experience to 4 years was to obtain data that reflect midwives' preservice education (PSE) and recent in-service training, rather than expertise gathered over long years of practice. Midwives having $<6$ months experience were also excluded, as they were not expected to have enough practice and training opportunities to make meaningful judgments. Each respective regional health bureau sent invitation letters to geographically representative health centers and hospitals in their jurisdiction to identify eligible midwives for recruitment. Each facility, in turn, purposively selected one appropriate midwife to participate in the study.

\section{Variables}

We drafted a midwifery task list from national scopes of practice, curricula, and job descriptions and validated it in a national expert panel workshop. The expert panel included midwifery educators and practitioners from different institutions, as well as representatives from the Federal Ministry of Health and the Ethiopian Midwifery Association. The final task list had 86 midwifery tasks including professional duties, general service delivery tasks, reproductive and maternity care tasks, labor and delivery tasks, and community/public health tasks. Three tasks were excluded later, as they were thought to be outside of midwifery scope of practice. Study participants made four judgments about each task. The first question was about frequency (how often did a participant perform a task?). The possible responses were daily (completed a task at least once per day), weekly (completed a task less often than daily, but at least once per week), monthly (completed a task less often than weekly, but at least once per month), rarely (completed a task less often than monthly), and never (lacked the opportunity or capability to perform a task). The second question concerned criticality (how critical is timely and effective performance of a task for client and/or population health outcomes?). The response options were high (failure to complete a task correctly or in a timely manner will lead to client death, permanent disability, or major impact on public health), moderate (failure to complete a task correctly or in a timely manner may lead to serious client discomfort, short-term disability, or moderate impact on public health), and low (failure to complete a task correctly or in a timely manner 
will lead to minimal impact on client or public health). The third question was about performance (how competent is the participant in performing a task?). The possible responses were proficient (expert at a task or can perform a task so well that s/he feels comfortable supervising others), competent (capable of performing a task safely, although may ask for supervision from a more experienced provider), and not capable (not comfortable performing a task; may cause harm if a task is performed without supervision). The fourth question concerned location or timing of training (when and where did the participant learn to perform a task?). The response options were PSE (received formal training as part of the PSE), in-service training (received formal training at some point after graduation), on-the-job training (received informal training from coworkers or supervisor, once began working), and not trained (received no formal or informal training for a task). We also collected data on sociodemographic variables including age, sex, region, qualification (diploma or bachelor degree), type of facility (health center or hospital), and length of work experience.

\section{Measurement}

We used a structured self-administered questionnaire with a validated task list to collect data. In each region, the study participants gathered at one place for a data collection workshop and completed the questionnaires individually with facilitation support from an expert midwife. Data collectors verified eligibility of study participants before the start of data collection workshops.

\section{Data analysis}

We used Statistical Package for the Social Sciences, Version 20 (IBM Corporation, Armonk, NY, USA) for data analysis. Descriptive statistics included frequencies and means for the four key variables and sociodemographic characteristics. Further analysis examined response combinations to identify priority areas for PSE strengthening, in-service training, and licensing exam development. We identified priority PSE gaps by selecting critical tasks with a combination of relatively low "trained in PSE", high "not trained", and high "not capable" responses. Top needs for in-service training prioritized critical tasks with high percentage of responses for "not capable" and "never done".

We considered responses to "criticality" and "frequency" variables to determine the level of emphasis in midwifery licensing exam. ${ }^{12}$ Grouped task lists in seven categories represented broad midwifery practice areas, namely, family planning, antenatal care, labor and delivery, postpartum care, gynecology care, care for the newborn and under-five child, and community/public health. We then applied the following steps to determine the percentage distribution of exam among the seven categories. First, we calculated the mean frequency and criticality score for each task, ranging from 1 (denoting never) to 5 (denoting daily) and from 1 (denoting low criticality) to 3 (denoting high criticality), respectively. We then calculated the composite mean score for each task (range was 2-8). We reviewed tasks with borderline composite mean scores $(3<$ "X" $<5)$ for possible elimination and calculated the average of composite mean scores for each category. Finally, we summed the category averages and computed the proportion of each category out of the total.

We complemented results from the task analysis study with subjective ratings from 32 experts during licensing exam writing workshop in February 2015. Item writers assigned percentage weight to each of the seven categories. We computed the mean of the expert assessments for each category and averaged it with the results from the survey.

\section{Data quality assurance}

The task list was developed based on national documents and validated in an expert panel workshop. A 5-day data collection training was conducted prior to field work. Training topics included introduction to task analysis methodology, study protocol, data storage, and ethical issues. Participants practiced data collection techniques in a role-play format after discussing the task list. Proficient midwives recruited from each region facilitated the data collection workshop and experts from the Federal Ministry of Health, Ethiopian Midwifery Association, and Jhpiego supervised the data collection process.

\section{Ethical clearance}

We obtained ethical clearance for the study from the Johns Hopkins University Institutional Review Board Office and approval from the Ethiopian Ministry of Health and respective regional health bureaus. Informed verbal consent was also obtained from the study participants prior to data collection.

\section{Results Sociodemographic characteristics}

One hundred and thirty-eight midwives selected from six regional states and one city administration participated in the study, giving a response rate of $98.6 \%$ (138/140). With regard to sociodemographic characteristics, majority of the respondents were females $(80.4 \%)$, younger than 25 years 
(62.3\%), had a diploma/vocational qualification $(81.9 \%)$, worked in health centers $(60.9 \%)$, and had 2 years or less of work experience as a midwife (58\%). The mean duration of service was 2.6 years (Table 1 ).

\section{Analysis of tasks performed by recently qualified midwives}

Table 2 summarizes the responses of study participants to frequency, criticality, competence, and timing/location of training questions by competency domain. Approximately $90 \%$ of respondents recognized the importance of midwifery tasks and felt they were capable of performing them. More than half of them also reported performing midwifery tasks frequently and having learned them during PSE. Furthermore, the majority of study participants said they provided family planning $(58.7 \%)$, antenatal care $(73.2 \%)$, normal delivery $(82.6 \%)$, postpartum care $(76.8 \%)$, and essential newborn care $(79.7 \%)$ services on a daily basis (data not shown).

Although all tasks were deemed critical by the vast majority $(85.2 \%-92.7 \%)$ of study participants, more than $10 \%$ of respondents rated all but antenatal care, normal labor and delivery, and child health care tasks as of low importance. Likewise, although an overwhelming majority (81.3\%-97.3\%) said they were capable of performing midwifery tasks, a sizable proportion (11.2\%-18.7\%)

Table I Sociodemographic characteristics of the study participants $(\mathrm{N}=138)$

\begin{tabular}{ll}
\hline Variable & Frequency (\%) \\
\hline Sex & \\
Male & $27(19.6)$ \\
Female & $111(80.4)$ \\
Age, years & \\
I9-24 & $86(62.3)$ \\
$25-45$ & $52(37.7)$ \\
Region & \\
Tigray & $20(14.5)$ \\
Amhara & $20(14.5)$ \\
Oromia & $20(14.5)$ \\
Somali & $22(15.9)$ \\
SNNP & $20(14.5)$ \\
Harari & $16(11.6)$ \\
Addis Ababa & $20(14.5)$ \\
Facility type & \\
Health center & $84(60.9)$ \\
Hospital & $54(39.1)$ \\
Education & \\
Diploma & $113(81.9)$ \\
Bachelor degree & $25(18.1)$ \\
Year of service & \\
$<1$ & $7(5.1)$ \\
I-2 & $73(52.9)$ \\
3-4 & $58(42)$ \\
\hline Abbrevation SNNPS &
\end{tabular}

Abbreviation: SNNP, Southern Nations, Nationalities, and Peoples. reported competence gaps in gynecology, obstetric complications, and community/public health tasks. These three task categories were also the least frequently performed tasks. Although PSE was the predominant time of learning, a substantial percentage $(28.8 \%-50.0 \%)$ of respondents learned midwifery tasks by in-service training and informal on-the-job learning. The in-service/on-the-job modalities played a particularly prominent role in learning HIV/ prevention of mother to child transmission of HIV (PMTCT) competencies and professional duties. Gynecology, public health, and obstetric complications had notable response rates $(9.5 \%-12.0 \%)$ for never being trained.

\section{Gaps in education and needs for training}

Table 3 summarizes the top 20 gaps in preservice midwifery education. Twenty critical tasks had relatively low "trained in PSE", high "not trained", and high "not capable" responses. The least frequently learned tasks in PSE were membership in professional association, participating in policy dialog, training and supervising community health workers (CHWs), and performing manual vacuum aspiration (MVA). The most frequently mentioned tasks for "not trained" were detecting reproductive organ cancers and tumors, performing MVA, membership in professional association, identifying injuries of pelvic muscles, surveillance of maternal and newborn health conditions, training and supervising CHWs, and preparing and assisting with operations. The biggest competence gaps (hence top in-service training needs) were in detecting reproductive organ cancers and tumors, performing MVA, assisting with operations, identifying pelvic muscle injuries, membership in professional association, diagnosis and management of ectopic pregnancy, diagnosis and management of abortion, induction and augmentation, and identifying, counseling, and preventing infertility.

\section{Exam blueprint for midwifery licensing exam}

The results from the task analysis study suggested the midwifery licensing exam composition to include $14.9 \%$ family planning, $15.1 \%$ antenatal care, $14.7 \%$ labor and delivery, $15.3 \%$ postpartum care, $13.2 \%$ gynecology, $14.5 \%$ newborn and child health, and $12.4 \%$ public health questions. Expert ratings during item writing workshop for licensing exam generated higher emphasis for antenatal ( +3.4 points $)$ and labor and delivery (+10.2 points) categories, but lesser emphasis for family planning ( -2.7 points), postpartum ( -2.4 points), gynecology ( -1.6 points), underfive ( -3.5 points), and public health ( -3.8 points) categories. Averaged percentages from the task analysis study and the 
Table 2 Analysis of tasks performed by recently qualified midwives in terms of frequency, criticality, competence, and location of training

\begin{tabular}{|c|c|c|c|c|c|c|c|c|c|c|}
\hline \multirow{2}{*}{$\begin{array}{l}\text { Task domains } \\
\text { (\# of tasks) }\end{array}$} & \multicolumn{3}{|c|}{ Frequency (\%) } & \multicolumn{2}{|c|}{ Criticality (\%) } & \multicolumn{2}{|c|}{ Competence (\%) } & \multicolumn{3}{|c|}{ Location (\%) } \\
\hline & $\mathbf{H}$ & M & $\mathbf{L}$ & $\mathbf{I}$ & $\mathbf{L}$ & C & NC & PSE & IST & NT \\
\hline Professional duties (16) & 66.7 & 8.4 & 24.8 & 85.2 & 14.8 & 93.4 & 6.6 & 44.2 & 47.8 & 8.0 \\
\hline General service (II) & 79.1 & 8.0 & 12.8 & 88.4 & 11.6 & 95 & 5.0 & 55.5 & 41.3 & 3.1 \\
\hline Family planning (3) & 74.6 & 4.8 & 20.5 & 87.9 & 12.1 & 93.7 & 6.3 & 58.7 & 36.7 & 4.6 \\
\hline Antenatal care (5) & 75.1 & 7.1 & 17.8 & 92.6 & 7.4 & 97.3 & 2.7 & 64.5 & 34.0 & $\mathrm{I} .4$ \\
\hline HIV/PMTCT (3) & 81.2 & 5.1 & 13.8 & 89.6 & 10.4 & 95.7 & 4.3 & 46.1 & 50.0 & 3.8 \\
\hline Labor and delivery (3) & 77.0 & 6.5 & 16.4 & 90.8 & 9.2 & 93.1 & 6.9 & 56.1 & 38.7 & 5.2 \\
\hline Postnatal care (4) & 67.8 & 7.9 & 24.2 & 89.5 & 10.5 & 90.2 & 9.8 & 64.9 & 28.8 & 6.3 \\
\hline Obstetric complications (I0) & 49.3 & 10.8 & 39.8 & 88.1 & 11.9 & 85 & 14.0 & 58.5 & 32.0 & 9.5 \\
\hline Gynecology care (8) & 41.4 & 9.1 & 49.6 & 87.4 & 12.6 & 81.3 & 18.7 & 57.3 & 30.7 & 12.0 \\
\hline Under-five child (2) & 57.0 & 13.1 & 30.1 & 92.7 & 7.3 & 93.1 & 6.9 & 60.9 & 35.2 & 4.0 \\
\hline Public health (I8) & 36.2 & 15.4 & 48.3 & 87.2 & 12.8 & 88.8 & 11.2 & 53.2 & 35.5 & 11.3 \\
\hline Total (83) & 63.9 & 8.9 & 27.2 & 89 & 11.0 & 91.8 & 8.2 & 56.3 & 37.5 & 6.2 \\
\hline
\end{tabular}

Notes: "H" denotes high frequency and includes daily and weekly responses; "M" denotes moderate frequency and means monthly response; and " $L$ " denotes low frequency and includes rarely and never responses. Within criticality, "l" denotes important and includes high and moderate responses and "L" denotes low importance. Within competence, "C" denotes competent and includes proficient and competent responses and "NC" denotes not capable. In location of training, PSE refers to preservice education, IST refers to in-service training and includes in-service training and informal on-the-job learning, and NT means not trained.

Abbreviation: HIV/PMTCT, human immunodeficiency virus/prevention of mother to child transmission of HIV.

expert ratings resulted in a final exam distribution plan composed of labor and delivery, antenatal care, postpartum care, family planning, care for the newborn and under-five child, gynecology, and public health questions, in decreasing frequency (Figure 1).

\section{Discussion}

Our study examined midwifery practice and generated evidence to strengthen midwifery education, care, and regulation. Strengths of the study include use of a nationally representative sample from geographic and practice settings for midwives working in the public sector. A limitation to task analysis surveys is that the data is self-reported and there is potential for responses to be ones that the respondents considered most acceptable. We tried to mitigate this with assurance to the study participants that their responses would not be linked to their names and that reporting would be aggregate. Another limitation was that some of the

Table 3 Top 20 gaps in preservice midwifery education

\begin{tabular}{|c|c|c|c|c|c|}
\hline Tasks & $\%$ Critical & $\%$ Trained in PSE & $\%$ Not trained & $\%$ Not capable & $\%$ Never done \\
\hline Membership in professional organization & 78.2 & 23.9 & 29.0 & 23.9 & 51.4 \\
\hline Participate in policy dialog to advance $\mathrm{MNCH}$ & 88.4 & 25.4 & 14.5 & 13.0 & 23.2 \\
\hline Train and supervise CHWs & 86.2 & 30.4 & 18.8 & 14.5 & 37.7 \\
\hline Perform manual vacuum aspiration & 82.7 & 31.2 & 29.0 & 37.7 & 47.1 \\
\hline Coordinate educational outreach programs & 81.2 & 34.1 & 13.8 & 18.8 & 30.4 \\
\hline Provide ARV for PMTCT & 88.4 & 34.8 & 12.3 & 16.7 & 16.7 \\
\hline Collaborate with community groups & 84.7 & 35.5 & 9.4 & 12.3 & 14.5 \\
\hline Conduct research activities & 70.3 & 37.0 & 15.9 & 17.4 & 32.6 \\
\hline Function as a member of health team & 81.2 & 37.0 & 14.5 & 12.3 & 25.4 \\
\hline Prepare and assist with operations & 68.1 & 42.8 & 18.1 & 26.1 & 34.8 \\
\hline Surveillance of $\mathrm{MNCH}$ conditions & 86.3 & 45.7 & 20.3 & 12.3 & 30.4 \\
\hline Detect cancer of reproductive organs & 82.6 & 46.4 & 29.0 & 42.8 & 55.8 \\
\hline Identify injuries of pelvic muscles & 83.3 & 47.8 & 20.3 & 25.4 & 21.7 \\
\hline $\begin{array}{l}\text { Management of women who have } \\
\text { experienced sexual assault }\end{array}$ & 89.9 & 48.6 & 11.6 & 18.1 & 21.0 \\
\hline Diagnose and manage abortion & 84.1 & 49.3 & 17.4 & 21.7 & 23.2 \\
\hline Detect reproductive organ tumors & 79.8 & 51.4 & 19.6 & 31.2 & 34.1 \\
\hline Operative vaginal deliveries & 89.1 & 56.5 & 9.4 & 13.8 & 19.6 \\
\hline Diagnose and manage ectopic pregnancy & 85.5 & 63.8 & 13.0 & 23.2 & 31.9 \\
\hline Identify, counsel, and prevent infertility & 88.4 & 63.8 & 8.7 & 20.3 & 23.9 \\
\hline Perform induction and augmentation & 78.3 & 63.8 & 5.8 & 21.0 & 29.0 \\
\hline
\end{tabular}

Abbreviations: $\mathrm{CHWs}$, community health workers; MNCH, maternal, newborn, and child health; PSE, preservice education; ARV PMTCT, anti-retroviral drug for prevention of mother to child transmission of HIV. 


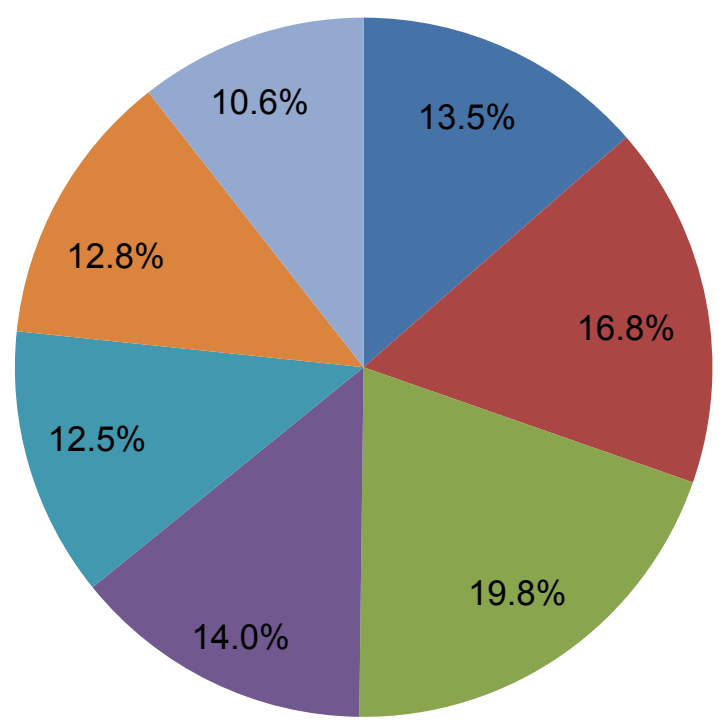

Family planning
Antenatal care
Labor and delivery care
Postpartum care
Gynecology
Care for the newborn and under-five
Public health

Figure I Recommended percentage distribution of midwifery licensing exam based on the results of task analysis study and expert rating.

tasks were not discrete enough, making interpretation less straightforward.

The proportion of male midwives in our study might appear high compared to other countries, but it reflects the Ethiopia midwifery workforce and is consistent with a previous study conducted with graduating midwifery students. ${ }^{11}$

Our results confirmed that midwives are crucial providers of reproductive, maternal, newborn, and child health care services. This supports the Ethiopian government's policy strategy to scale up midwifery education. Most midwives not only understood the significance of their tasks to health and well-being of women and children but also reported that they performed them competently and routinely. Study participants participated in gynecology, public health, and obstetric complications management less often, probably due to a combination of lack of opportunity and capability (Table 2). Task analysis studies from sub-Saharan African countries have also reported largely similar findings. A Liberian study reported that most (60\%-80\%) midwives completed their tasks frequently, except for obstetric complications and child health interventions. ${ }^{13}$ A Malawi study found that majority of nurse-midwife technicians were competent in midwifery and infectious diseases and performed them frequently, but were not competent at the less common tasks related to cancer, public health, and obstetric complications. ${ }^{14}$ Majority of maternal and child health nurses $(57.9 \%-75.1 \%)$ in Mozambique frequently provided antenatal, labor and delivery, newborn and postpartum care, but rarely participated in complications management, gynecology, and public health. ${ }^{15}$

Our study revealed the presence of significant gaps in the content and quality of preservice midwifery education in the areas of obstetric complications, gynecology, public health, professional duties, and prevention of mother-to-child transmission of HIV. A large proportion of respondents did not learn several tasks that are within expected midwifery practice in PSE. A number of tasks learned in PSE also had low levels of reported competence (Table 3). Even though small, the percentage of participants who thought midwifery tasks were of low importance was not negligible. This is potentially a concern, as midwives may not want to learn and do tasks that they think are less important. Lack of appreciation of task importance might be due to lack of knowledge, which possibly indicates a need for greater emphasis in PSE (Table 2).

The weakness we found in preservice midwifery education is consistent with findings from other studies in Ethiopia, Africa, and Asia. Assessment of graduating midwifery students in Ethiopia showed low achievement of competencies, particularly in performance of MVA, vacuum-assisted delivery, partograph use, and integrated management of childhood illnesses. ${ }^{11}$ A mixed methods study identified insufficient PSE as a key barrier to provision of quality emergency obstetric care in Addis Ababa, Ethiopia. ${ }^{16}$ A task analysis of nurse-midwife technicians in Malawi reported low levels of competence in obstetric complications management. ${ }^{14}$ A similar study in Liberia found that $13 \%-20 \%$ of midwives did not receive PSE on some antenatal, normal delivery, and postnatal care tasks. ${ }^{13}$ A study in Mali reported that midwives scored $66.4 \%$ on assessment of emergency obstetric care knowledge and skills using clinical vignettes. ${ }^{17}$ Evaluation of midwifery graduates' performance in Afghanistan found gaps in retention of clinical competencies with more pronounced deficits in shock management and MVA. ${ }^{18}$ An Indian study indicated that final year midwifery students had low level of confidence in basic midwifery competencies for antepartum, intrapartum, postpartum, and newborn care. ${ }^{19}$ The State of the World's Midwifery Report 
2014 covering 73 low- and middle-income countries also found pervasive gaps in midwifery education. ${ }^{8}$

The possible gaps in PSE and competence of midwives have important implications. The substantial gaps in management of obstetric complications are particularly critical in view of their importance for maternal and newborn survival ${ }^{20,21}$ and the global commitment to end preventable maternal and child deaths. ${ }^{22}$ Reproductive organ cancers are also a leading cause of morbidity and mortality for women in low- and middle-income countries. ${ }^{23}$ Breast, cervical, and ovarian cancers are the most common cancers among Ethiopian women and account for half of cancer-related deaths. ${ }^{24}$ The capacity gap for detecting reproductive organ cancers is significant as it constrains the ability to increase access to screening and treatment services in Ethiopia. ${ }^{25}$ Infertility is also a major, but neglected public health problem in low-income countries including Ethiopia. ${ }^{26}$ Prevention and treatment services are limited, partly due to lack of trained staff. ${ }^{27-29}$ As key reproductive health care providers, midwives should be able to provide basic infertility prevention, diagnostic, and treatment services. Violence against women is also a pervasive public health problem with impacts on sexual, reproductive, and perinatal health outcomes. ${ }^{30}$ As women's health care providers, midwives have an important role to play in identifying victims of violence and providing clinical care. ${ }^{31}$

Midwives can contribute even more to strengthen health systems and improve RMNCH outcomes if they actively participate in public health, research, and policy activities beyond clinical care. Addressing the gaps in preservice content for these areas is important to increase midwifery participation. ${ }^{32-35}$ Health promotion and disease prevention are central to midwifery practice, ${ }^{5,36}$ and midwives need public health knowledge and skills to carry out this function effectively. Improving the health of women and children requires understanding the social determinants of health and partnership, ${ }^{37}$ which in turn require public health and policy advocacy skills. The education gap in preparing midwives to train and supervise CHWs represents a missed opportunity because health extension workers (who are the CHWs in Ethiopia) are the frontline RMNCH care providers for the rural Ethiopian population. ${ }^{38,39}$ Midwives are expected to support and collaborate with them in promoting and providing family health services such as family planning, antenatal care, assisted delivery, vaccination, and treatment of common childhood illnesses.

The International Confederation of Midwives regards organization of midwives in an association as one of the three pillars for a strong midwifery profession and an important force to improve the health of women and children. ${ }^{40}$ However, our study clearly indicated that PSE seldom addressed membership in professional association and, possibly consequently, the majority of respondents were not members of a professional association. A significant percentage did not believe membership was important. The perception gap may be an indication that midwives did not believe they would benefit from membership in a professional association, which suggests that the local midwifery association needs to do more to educate and attract midwives. Membership in a professional association may strengthen professional identity and increase motivation and performance. ${ }^{41}$

Ethiopia is one of the 22 countries with the highest number of pregnant women living with HIV. In view of the increased efforts required to achieve the global goal of eliminating new child infections, ${ }^{42}$ the inadequacy in PMTCT education and competence is significant. In-service training appears to have played a bigger role than PSE and compensated for much of the education gap in PMTCT. This, however, warrants further work to integrate the in-service content in preservice curriculum and improve competence in this area.

Midwives can have a great impact in improving $\mathrm{RMNCH}$ outcomes. Competent midwives can provide most of the essential care needed to prevent most maternal and newborn deaths. ${ }^{5-8}$ However, realizing the full benefits of midwifery care for the health and well-being of women and children requires reviewing and strengthening midwifery education with focus on priority gaps identified in our study.

Even more urgent is the need to enhance the capacity of the existing midwifery workforce. A substantial proportion of currently practicing midwives need opportunities for improving their competence in obstetric complications, reproductive organ cancers, and infertility. Because these are low-frequency events, opportunities for informal on-the-job learning and practice are limited. An alternative is requiring an in-service training intervention. Several studies from low-resource settings have demonstrated that it is feasible to train midlevel health workers to provide safe and effective emergency obstetric care ${ }^{43-49}$ and cervical cancer screening. ${ }^{50,51}$ Basic infertility prevention and management services can be offered in low-resource settings. ${ }^{27-29} \mathrm{We}$ also know from literature that training delivered using effective techniques, repeated over time, and organized in a workplacelike setting can improve the performance. ${ }^{52}$

Professional association meetings offer an important avenue to access continuing education. A challenge is the 
low membership rates reported by respondents. If local professional associations can inform and motivate potential members, it would be an important way to provide continuing education.

Conducting task analysis study is foundational for developing a valid and legally defensible licensing examination, as the content of a licensing examination should be closely related to the tasks that a health professional performs on the job. ${ }^{12,53,54}$ The American Midwifery Certification Board ${ }^{12}$ and the National Council of State Boards of Nursing ${ }^{54}$ periodically conduct task analysis studies to guide development of exam content. Our findings suggested a licensing exam should systematically sample all areas of midwifery practice, including reproductive, maternal, and child health services to individuals and populations, but with greater emphasis on antepartum, intrapartum, and postpartum care. This is consistent with test specification weights recommended in the latest task analysis by the American Midwifery Certification Board, which suggested a broad sampling of midwifery practice and greater emphasis on antepartum (22\%), intrapartum (22\%), and postpartum (16\%) care. ${ }^{12}$ Our findings served as the basis for development of a blueprint for the first national licensing exam for bachelor of science in midwifery, which was successfully administered in 2015 . The exam provides a standard that new graduates must meet to enter the workforce. In addition, a licensing exam developed in this manner can improve the quality and relevance of midwifery education through feedback to midwifery schools.

\section{Conclusion}

Midwives are important providers of RMNCH services, and the Government of Ethiopia should continue to invest in midwifery as a key strategy to achieve national health development goals. However, there are substantial PSE gaps that need addressing through strengthening the content and quality of midwifery education with focus on obstetric complications, gynecology, public health, professional duties, and PMTCT in light of national and global priorities. Our study also revealed the presence of significant gaps in ability of the existing midwifery workforce to identify and/or manage obstetric complications, reproductive organ cancers, and infertility. Strengthening the existing midwifery workforce through targeted in-service training is urgently needed in order to realize the full potential of midwifery care to provide services to Ethiopian families. The majority of midwives were not a member of a professional association, indicating the need for greater effort by the national midwifery association to attract and recruit midwives. The Strengthening Human Resources for Health Project should support the Ministry of Health to revise midwifery curricula and develop need-based in-service training courses. The Ethiopian Midwifery Association could collaborate in these efforts and play a role in providing continuing education and in-service courses.

Our study also served as the primary basis for developing the first national licensing exam for graduates of bachelor of science in midwifery. This contributes to assuring the quality and relevance of midwifery education and the midwifery workforce. We recommend that task analysis be conducted periodically to inform continuous improvement of midwifery education and practice. Future studies should involve larger sample populations, apply probabilistic sampling procedure, and develop a more specific task list.

\section{Acknowledgments}

This study was made possible by the generous support of the American people through the United States Agency for International Development under the Cooperative Agreement AID-663-A-12-0008. The contents are the responsibility of the authors and do not necessarily reflect the views of United States Agency for International Development or the US government. We are also grateful to the study participants and the Ministry of Health of the Federal Democratic Republic of Ethiopia.

\section{Disclosure}

The authors report no conflicts of interest in this work.

\section{References}

1. WHO. Transforming and Scaling Up Health Professionals' Education and Training: World Health Organization Guidelines 2013. Geneva: World Health Organization; 2013.

2. Campbell J, Dussault G, Buchan J, et al. A universal truth: no health without a workforce. Forum report, Third Global Forum on Human Resources for Health, Recife, Brazil. Geneva: Global Health Workforce Alliance and World Health Organization; 2013.

3. Akiko M, Araujo E, Cashin C, Harris J, Ikegami N, Reich MR. Universal Health Coverage for Inclusive and Sustainable Development: A Synthesis of 11 Country Case Studies. Directions in Development. Washington DC: World Bank; 2014.

4. USAID. USAID's Vision for Health Systems Strengthening (2015-2019). Washington DC: United States Agency for International Development; 2015.

5. Renfrew MJ, McFadden A, Bastos MH, et al. Midwifery and quality care: findings from a new evidence informed framework for maternal and newborn care. Lancet. 2014;384:1129-1145.

6. Homer CS, Friberg IK, Dias MAB, et al. The projected effect of scaling up midwifery. Lancet. 2014;384:1146-1157.

7. Hoope-Bender Pt, Bernis Ld, Campbell J, et al. Improvement of maternal and newborn health through midwifery. Lancet. 2014;384: $1226-1235$. 
8. UNFPA. The State of the World's Midwifery 2014: A Universal Pathway. A Woman's Right to Health. New York: The United Nations Population Fund, the International Confederation of Midwives, the World Health Organization; 2014.

9. Van Lerberghe W, Matthews Z, Achadi E, et al. Country experience with strengthening of health systems and deployment of midwives in countries with high maternal mortality. Lancet. 2014;384:1215-1225.

10. FMOH. Human Resource for Health Strategic Plan (2009-2025). Addis Ababa: Federal Democratic Republic of Ethiopia, Ministry of Health; 2015.

11. Yigzaw T, Ayalew F, Kim Y-M, et al. How well does pre-service education prepare midwives for practice: competence assessment of midwifery students at the point of graduation in Ethiopia. BMC Med Educ. 2015;15:130.

12. AMCB. 2012 Task Analysis Report: A Report of Midwifery Practice. Linthicum, MD: American Midwifery Certification Board; 2012.

13. Udaya A, Subah M, Drake M, Ng C, Johnson P. Task analysis: An evidence-based methodology for strengthening education and training of nurses and midwives in Liberia. Int J Nurs Midwifery. 2011;3(9): $118-127$.

14. Jacob S, Holman J, Msolomba R, et al. Using task analysis to strengthen nursing and midwifery pre-service education in Malawi. Int $J$ Nurs Midwifery. 2015;7(5):84-103.

15. Dgedge M, Mendoza A, Necochea E, Bossemeyer D, Rajabo M, Fullerton J. Assessment of the nursing skill mix in Mozambique using a task analysis methodology. Hum Resour Health. 2014;12:5.

16. Austin A, Gulema H, Beliza M, et al. Barriers to providing quality emergency obstetric care in Addis Ababa, Ethiopia: healthcare providers' perspectives on training, referrals and supervision, a mixed methods study. BMC Pregnancy Childbirth. 2015;15:74.

17. Huchon C, Arsenault C, Tourigny C, et al. Obstetric competence among referral healthcare providers in Mali. Int J Gynaecol Obstet. 2014; 126(1):56-59.

18. Zainullah P, Ansari N, Yari K, et al. Establishing midwifery in low-resource settings: guidance from a mixed-methods evaluation of the Afghanistan midwifery education program. Midwifery. 2013;30(10):1056-1062.

19. Sharma B, Hildingsson I, Johansson E, Prakasamma M, Ramani KV, Christensson K. Do the pre-service education programmes for midwives in India prepare confident 'registered midwives'? A survey from India. Glob Health Action. 2015;8:29553.

20. Say L, Chou D, Gemmill A, et al. Global causes of maternal death: a WHO systematic analysis. Lancet Glob Health. 2014;2:e323-e333.

21. Bhutta ZA, Das JK, Bahl R, et al. Can available interventions end preventable deaths in mothers, newborn babies, and stillbirths, and at what cost? Lancet. 2014;384:347-370.

22. WHO. Health in 2015: From MDGs, Millennium Development Goals to SDGs, Sustainable Development Goals. Geneva: World Health Organization; 2015.

23. WHO. WHO Guidance Note: Comprehensive Cervical Cancer Prevention and Control: A Healthier Future for Girls and Women. Geneva: The World Health Organization; 2013.

24. WHO. Cancer Country Profiles 2014, Ethiopia. Geneva: The World Health Organization; 2014. Available from: http://www.who.int/cancer/ country-profiles/eth_en.pdf?ua=1. Accessed December 30, 2015.

25. FMOH. Health Sector Transformation Plan (2015/2016-2019/2020). Addis Ababa: Federal Democratic Republic of Ethiopia, Ministry of Health; 2015. Available from: http://www.moh.gov.et/ documents/26765/0/Health+Sector+Transformation+Plan/5542a23a9bc7-46a2-8c1f-8b32c2603208?version=1.0. Accessed December 30, 2015.

26. Mascarenhas MN, Flaxman SR, Boerma T, Vanderpoel S, Stevens GA. National, regional, and global trends in infertility prevalence since 1990: a systematic analysis of 277 health surveys. PLoS Med. 2012;9(12): e1001356.

27. Hammarberg K, Kirkman M. Infertility in resource-constrained settings: moving towards amelioration. Reprod Biomed Online. 2013; 26:189-195.
28. Ombelet W, Cooke I, Dyer S, Serour G, Devroey P. Infertility and the provision of infertility medical services in developing countries. Hum Reprod Update. 2008;14(6):605-621.

29. Sharma S, Mittal S, Aggarwal P. Management of infertility in low resource countries. BJOG. 2009;116(Suppl 1):77-83.

30. WHO. Global and Regional Estimates of Violence Against Women: Prevalence and Health Effects of Intimate Partner Violence and Non-Partner Sexual Violence. Geneva: The World Health Organization; 2013.

31. WHO. Responding to Intimate Partner Violence and Sexual Violence Against Women: WHO Clinical and Policy Guidelines. Geneva: The World Health Organization; 2013.

32. ICM. International code of ethics for midwives. Adopted at 2008 Glasgow Council Meeting; 2008. Reviewed and adopted at the Prague Council Meeting; 2014. Available from: http://www. internationalmidwives.org. Accessed December 30, 2015.

33. ICM. The role of the midwife in research. Adopted at 2008 Glasgow Council Meeting; 2008. Reviewed and adopted at the Prague Council Meeting; 2014. Available from: http://www.internationalmidwives.org/ Position Statement. Accessed December 30, 2015.

34. Chief Nursing Officers of England, Northern Ireland, Scotland, and Wales. Midwifery 2020: delivering expectations. Cambridge: Jill Rogers Associates; 2010. Available from: http://www.midwifery2020.org. Accessed December 30, 2015.

35. Gebbie K, Rosenstock L, Hernandez LM, editors. Who Will Keep the Public Healthy? Educating Public Health Professionals for the 21st Century. Washington DC: National Academy of Sciences; 2003. Available from: http://www.nap.edu. Accessed December 31, 2015.

36. ICM. Essential competencies for basic midwifery practice 2010 Revised 2013. International Confederation of Midwives; 2013. Available from: http://www.internationalmidwives.org. Accessed December 31, 2015.

37. CSDH. Closing the Gap in a Generation: Health Equity Through Action on the Social Determinants of Health. Final Report of the Commission on Social Determinants of Health. Geneva: World Health Organization; 2008.

38. Mangham-Jefferies L, Mathewos B, Russell J, Bekele A. How do health extension workers in Ethiopia allocate their time? Hum Resour Health. 2014;12:61. Available from: http://www.human-resources-health.com/ content/12/1/61. Accessed May 12, 2016.

39. Karim AM, Admassu K, Schellenberg J, et al. Effect of Ethiopia's health extension program on maternal and newborn health care practices in 101 rural districts: a dose-response study. PLoS One. 2013;8(6):e65160.

40. ICM. The International Confederation of Midwives Dissemination Pack. Global standards, competencies and tools. The International Confederation of Midwives; 2014. Available from: http://www.internationalmidwives.org/assets/uploads/documents/ Dissemination/140508\%20Dissemination\%20ICM\%20V06.pdf. Accessed on May 12, 2016.

41. WHO. The World Health Report 2006. Geneva: World Health Organization; 2006.

42. UNAIDS. 2015 Progress Report on the Global Plan Towards the Elimination of New HIV Infections Among Children and Keeping their Mothers Alive. Geneva: Joint United Nations Program on HIV/AIDS; 2015.

43. Nelissen E, Ersdal H, Mduma E, et al. Helping mothers survive bleeding after birth: retention of knowledge, skills, and confidence nine months after obstetric simulation-based training. BMC Pregnancy Childbirth. 2015;15:190.

44. Evans CL, Johnson P, Bazant E, Bhatnagar N, Zgambo J, Khamis AR. Competency-based training "helping mothers survive: bleeding after birth" for providers from central and remote facilities in three countries. Int J Gynaecol Obstet. 2014;126(3):286-290.

45. Dresang LT, González MM, Beasley J, et al. The impact of advanced life support in obstetrics (ALSO) training in low-resource countries. Int J Gynaecol Obstet. 2015;131(2):209-215.

46. Klingberg-Allvin M, Cleeve A, Atuhairwe S, et al. Comparison of treatment of incomplete abortion with misoprostol by physicians and midwives at district level in Uganda: a randomized controlled equivalence trial. Lancet. 2015;385:2392-2398. 
47. Barnard S, Kim C, Park MH, Ngo TD. Doctors or mi-level providers for abortion. Cochrane Database Syst Rev. 2015;7:CD011242.

48. Warriner IK, Meirik O, Hoffman M, et al. Rates of complication in first-trimester manual vacuum aspiration abortion done by doctors and mid-level providers in South Africa and Vietnam: a randomised controlled equivalence trial. Lancet. 2006;368:1965-1972.

49. Warriner IK, Wang D, Huong NT, et al. Can midlevel health-care providers administer early medical abortion as safely and effectively as doctors? A randomised controlled equivalence trial in Nepal. Lancet. 2011;377: $1155-1161$.

50. Blumenthal P, Lauterbach M, Sellors J, Sankaranarayanan R. Training for cervical cancer prevention programs in low-resource settings: Focus on visual inspection with acetic acid and cryotherapy. Int J Gynaecol Obstet. 2005;89(2):S30-S37.
51. Poli UR, Bidinger PD, Gowrishankar S. Visual Inspection with Acetic Acid (VIA) screening program: 7 years experience in early detection of cervical cancer and pre-cancers in rural South India. Indian $J$ Community Med. 2015;40(3):203-207.

52. Bluestone J, Johnson P, Fullerton J, Carr C, Alderman J, BonTempo J. Effective in-service training design and delivery: evidence from an integrative literature review. Hum Resour Health. 2013;11:51.

53. AERA. Standards for Educational and Psychological Testing. American Educational Research Association, American Psychological Association, National Council on Measurement in Education; 2014.

54. NCSBN. Report of Findings from the 2011 RNNursing Knowledge Survey. Chicago, IL: National Council of State Boards of Nursing; 2012.

\section{Publish your work in this journal}

The International Journal of Women's Health is an international, peerreviewed open-access journal publishing original research, reports, editorials, reviews and commentaries on all aspects of women's healthcare including gynecology, obstetrics, and breast cancer. The manuscript management system is completely online and includes

\section{Dovepress}

a very quick and fair peer-review system, which is all easy to use. Visit http://www.dovepress.com/testimonials.php to read real quotes from published authors. 